\title{
Plasma proteomic changes during therapeutic hypothermia in resuscitated patients after cardiac arrest
}

\author{
TEIJI ODA ${ }^{1}$, AKANE YAMAGUCHI $^{1}$, RYOSUKE ISHIDA $^{2}$, TETSURO NIKAI $^{3}$, \\ KOJI SHIMIZU ${ }^{1}$ and KEN-ICHI MATSUMOTO ${ }^{4}$
}

\author{
${ }^{1}$ Division of Thoracic and Cardiovascular Surgery, Department of Surgery, Shimane University Faculty of Medicine, \\ Izumo, Shimane 693-8501; ${ }^{2}$ Department of Emergency and Critical Care Medicine, Shimane Prefectural Central Hospital, \\ Izumo, Shimane 693-8555; ${ }^{3}$ Department of Anesthesiology, Shimane University Faculty of Medicine; \\ ${ }^{4}$ Department of Biosignaling and Radioisotope Experiment, Interdisciplinary Center for Science Research, \\ Organization for Research, Shimane University, Izumo, Shimane 693-8501, Japan
}

Received October 9, 2018; Accepted May 2, 2019

DOI: 10.3892/etm.2019.7649

\begin{abstract}
Hypothermia is used for several h during cardiac and aortic surgery to protect ischemic organs. Therapeutic hypothermia ( $\mathrm{TH}$ ) is used for $\leq 24 \mathrm{~h}$ as a treatment for comatose patients after the return of spontaneous circulation (ROSC) following cardiac arrest. The proteomic approach may provide unbiased data on alterations in the abundance of proteins during TH. The objective of this study was to assess the effects of cooling/rewarming on the plasma proteome during TH after ROSC and to identify the mechanism underlying its therapeutic effects. A total of nine comatose adult patients, resuscitated shortly after cardiac arrest, were cooled to $34^{\circ} \mathrm{C}$ for $24 \mathrm{~h}$ and slowly rewarmed to $36^{\circ} \mathrm{C}$. A quantitative gel-free proteomic analysis was performed using the isobaric tag for relative and absolute quantification labeling tandem mass spectrometry. Plasma samples were obtained prior to cooling and rewarming, and immediately after rewarming, from all patients during TH after ROSC. A total of 92 high-confidence proteins were identified. Statistically significant alterations were observed ( $>1.2$-fold increase or $<0.833$-fold decrease) in the levels of 15 of those proteins ( $\mathrm{P}=0.003-0.047)$, mainly proteins belonging to the acute-phase response or platelet degranulation. Unexpectedly, the levels of free hemoglobin (hemoglobin subunits $\alpha$ and $\beta$ ) were significantly downregulated during TH $(\mathrm{P}<0.05)$. The level of the terminal complement complex (SC5b-9) showed significant reduction after cooling $(\mathrm{P}=0.023)$. Although the acute-phase response proteins were upregulated, the abundance of complement proteins did not change, and the
\end{abstract}

Correspondence to: Professor Teiji Oda, Division of Thoracic and Cardiovascular Surgery, Department of Surgery, Shimane University Faculty of Medicine, 89-1 Enya-cho, Izumo, Shimane 693-8501, Japan

E-mail: toda@med.shimane-u.ac.jp

Key words: therapeutic hypothermia, complement activation, proteomics, hemoglobin, acute-phase response, inflammation levels of SC5b-9 and free hemoglobin decreased during TH in patients after ROSC.

\section{Introduction}

Therapeutic hypothermia (TH) is an effective therapy for comatose patients, improving outcome after return of spontaneous circulation (ROSC) following cardiac arrest with ventricular tachycardia or fibrillation as the initial rhythm (1). All comatose adult patients after ROSC following cardiac arrest should receive targeted temperature management (TTM), with a target temperature between $32^{\circ} \mathrm{C}$ and $36^{\circ} \mathrm{C}(2)$. However, the mechanism underlying the therapeutic effect of $\mathrm{TH}$ remains elusive. Following ROSC, the subsequent ischemic reperfusion results in extensive generation of free radicals, leading to systemic inflammatory response syndrome (SIRS) which may severely impact prognosis (3). This type of SIRS has been termed 'post-cardiac arrest syndrome' (PCAS), including systemic ischemia/reperfusion injury and the subsequent SIRS, as well as brain injury and myocardial dysfunction (4,5). However, these studies mainly evaluated the levels of cytokines $(3,6,7)$. In contrast, the proteomic approach may provide unbiased data on alterations in the abundance of proteins (8). Isobaric tag-based quantitative mass spectrometry has been recently introduced as a high-throughput technology (9). A previous plasma proteomics method using the isobaric tag for relative and absolute quantification (iTRAQ) labeling identified 262 proteins and showed that 2-3 h of deep hypothermic cardiopulmonary bypass (CPB) suppressed complement activation compared with normothermic CPB in aortic surgery (10). Because the cooling time in TH after cardiac arrest is longer than that reported in cardiac surgery, it may be easier to detect more proteins with their expression changes in samples of patients undergoing TH. However, such studies are rare. For the first time, we performed gel-free proteomic analysis of plasma samples in patients undergoing TH after ROSC. The objective of this study was to assess the effects of cooling/rewarming on the plasma proteome during $\mathrm{TH}$ after ROSC and identify the mechanism underlying its therapeutic effect. 


\section{Patients and methods}

Study population. This was a prospective, observational study including nine patients resuscitated from an in-hospital or out-of-hospital cardiac arrest and treated with TH (Table I). This prospective, cohort study was approved by the Ethics Committee of Shimane University Faculty of Medicine and Shimane Prefectural Central Hospital.

Patient management. All patients were admitted to the intensive care unit (ICU) of Shimane University Hospital and Shimane Prefectural Central Hospital and treated according to the protocol predetermined by the study investigators in both hospitals (Table SI). Written informed consent was provided by the relatives of the patients. All patients were rapidly cooled to $34^{\circ} \mathrm{C}$ through surface cooling using the Arctic Sun $^{\circledR} 5000$ Temperature Management System (Medivance, Louisville, CO, USA) and maintained at that temperature for $24 \mathrm{~h}$. Rewarming was performed slowly at a rate of $0.1^{\circ} \mathrm{C} /$ hour up to the target temperature of $36^{\circ} \mathrm{C}$ (Fig. 1). Patients were sedated using propofol or midazolam plus fentanyl. Shivering was treated with continuous infusion of rocuronium. All patients were admitted to the ICU, intubated, and mechanically ventilated according to the study protocol. The mean blood pressure was maintained between 60 and $80 \mathrm{mmHg}$, and diuresis was controlled at a rate of $>1 \mathrm{ml} / \mathrm{kg} / \mathrm{h}$. Blood glucose was controlled between 150 and $200 \mathrm{mg} / \mathrm{dl}$.

Data and sample collection. Demographic and clinical variables were collected from the electronic files of the patients. Three blood samples were collected from an arterial line into ethylenediaminetetraacetic acid (EDTA) tubes as follows: T1 (prior to cooling), T2 (prior to rewarming, after $24 \mathrm{~h}$ of hypothermia), and T3 (immediately after rewarming at $36^{\circ} \mathrm{C}$ ). Following collection, the blood samples were immediately centrifuged at $1,400 \mathrm{x} g$ for $5 \mathrm{~min}$, and the plasma layers were stored at $-80^{\circ} \mathrm{C}$.

Immunodepletion of abundant proteins. The two most abundant plasma proteins, albumin and immunoglobulin ( $\mathrm{Ig}) \mathrm{G}$, were eliminated using an immunodepletion column (Albumin and IgG Depletion SpinTrap; GE Healthcare, Buckinghamshire, UK) according to the manufacturer's instructions and as previously reported (10).

iTRAQ labeling and strong cation exchange chromatography. Samples were prepared according to the manufacturer's instructions (SCIEX, Concord, Canada) and as previously described (10). Briefly, equal amounts of immunodepleted $\mathrm{T} 1, \mathrm{~T} 2$, and $\mathrm{T} 3$ samples from each patient were denaturated and reduced, and cysteines were alkylated and digested using trypsin (SCIEX). Each digest was labeled with a different iTRAQ tag using the iTRAQ Reagent 4-plex kit (SCIEX). iTRAQ label 114 was chosen for the T1 samples, whereas iTRAQ labels 115,116 , or 117 were randomly selected for the T2 and T3 samples. Subsequently, the three samples from each patient were combined and fractionated into six fractions using strong cation exchange (SCX) chromatography according to the manufacturer's instructions (SCIEX). Each fraction was desalted according to the manufacturer's instructions (Waters, Milford, MA, USA).
Table I. Demographic data.

Demographics, $\mathrm{n}=9$

Data

Age

$72.6 \pm 14.6$

Male, n (\%)

$4(44.4 \%)$

Bystander-initiated BLS, n (\%)

$5(55.6 \%)$

$3.8 \pm 4.6$

Time between collapse to CPR, min

$14.3 \pm 4.6$

Time between collapse to ROSC, min

$154.7 \pm 75.0$

Time between collapse to start of cooling, min

$34.5 \pm 25.0$

temperature $34^{\circ} \mathrm{C}$, min

Time between initiation of rewarming to

target temperature $36^{\circ} \mathrm{C}$, $\mathrm{h}$

APACHE II score

$26.5 \pm 7.8$

$\mathrm{pH}$ at initial examination

$31.2 \pm 4.7$

$7.13 \pm 0.31$

$16.8 \pm 6.9$

$20.7 \pm 18.6$

$52.7 \pm 23.8$

$3(33.3 \%)$

$5(55.6 \%)$

$1(11.1 \%)$

BLS, basic

Data are presented as the mean \pm standard deviation. BLS, basic life support; CPR, cardiopulmonary resuscitation; ROSC, return of spontaneous circulation; APACHE II, Acute Physiology and Chronic Health Evaluation II; CPC, cerebral performance category.

Nano liquid chromatography (LC) and matrix-assisted laser desorption/ionization (MALDI)-time-of-flight (TOF)/TOF mass spectrometry (MS)/MS analysis. One fraction from the SCX chromatography was fractionated to 171 spots using a DiNa nanoLC system (KYA Tech, Tokyo, Japan) and collected onto an Opti-TOF LC/MALDI 384 target plate (SCIEX) in accordance with the manufacturer's instructions and as previously described (10). Spotted peptide samples were analyzed using a $5800 \mathrm{MALDI}-\mathrm{TOF} / \mathrm{TOF}$ MS/MS Analyzer and the TOF/TOF Series software (version 4.0, SCIEX). MS/MS data were analyzed using the ProteinPilot ${ }^{\mathrm{TM}}$ software (version 3.0) and the Paragon ${ }^{\mathrm{TM}}$ protein database (SCIEX). Quantitative alterations in protein levels at $\mathrm{T} 2$ or $\mathrm{T} 3$ were calculated using the iTRAQ ratios T2:T1 or T3:T1, respectively.

ITRAQ data analysis and bioinformatic analysis. Identified proteins were tested to determine if they fulfilled the following two criteria: i) A false discovery rate (FDR) $<5 \%$ (FDR was estimated through 'decoy database searching' using the ProteinPilot $^{\mathrm{TM}}$ software); and ii) protein confidence $>99 \%$ ('unused ProtScore' $>2$ ). Proteins fulfilling these criteria were defined as statistically significant $(10,11)$. The DAVID 6.8 software (available at https://david.ncifcrf.gov accessed December 5, 2017) was used to test for gene enrichment and functional annotation analysis $(12,13)$ of Gene Ontology terms (GO, available at http://www.geneontology.org accessed July 31,2018$)(14)$. If the number of identified genes in a particular GO term was significantly larger than the total number of genes in the entire genome classified by the same 


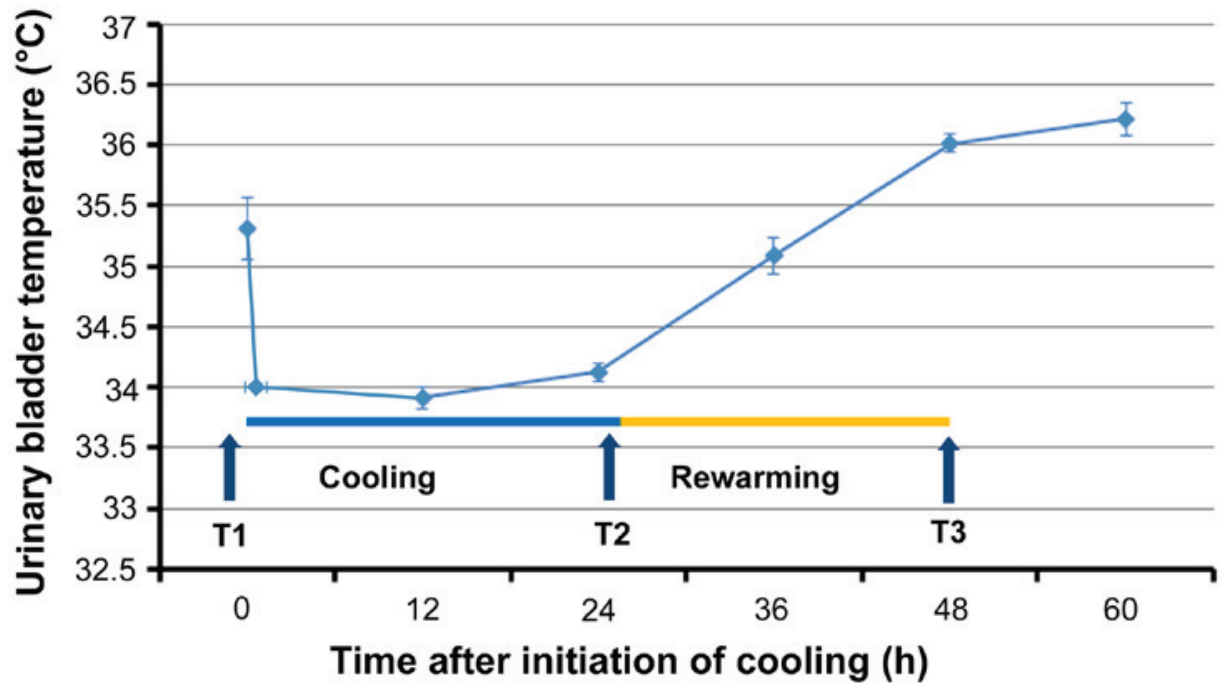

Figure 1. Changes in temperature during cooling and rewarming. Data are presented as the mean \pm standard error. T1, prior to cooling; T2, prior to rewarming; $\mathrm{T} 3$, immediately after rewarming.

GO term according to the binominal test, the GO term was termed 'enriched'. This suggested that a group of genes in the GO term may play an important role in the pathological process assessed by this study (13). The correction of multiple testing was performed using the EASE score, a modified Fisher's exact test, and Benjamini statistics $(12,13)$. The annotations of identified proteins were acquired from the Uniprot database (available at: http://www.uniprot.org/ accessed by July 31, 2018).

Western blot analysis and ELISA. Western blotting analysis was performed as previously described (11). Briefly, plasma samples were separated through sodium dodecyl sulfate-polyacrylamide gel electrophoresis (SDS-PAGE) and immunoblotted using the mouse monoclonal apolipoprotein A1 (ApoA1) antibody (Cell Signaling technology, Danvers, MA, USA), rabbit monoclonal apolipoprotein C3 (ApoC3) antibody (GeneTex, Irvine, CA, USA), mouse monoclonal Gelsolin (GSN) antibody (Abcam, Tokyo, Japan), and anti-rabbit IR dye 680-conjugated IgG (LI-COR, Lincoln, NE, USA). Protein bands were visualized using an Odyssey (LI-COR) Infrared Imaging System and their intensities were measured through densitometric analyses of ApoA1, APOC3, and GSN. To confirm equal levels of proteins per lane, nonspecific proteins stained with Coomassie Brilliant Blue (CBB) were analyzed. The average value of three independent experiments was used for statistical analysis. The levels of free hemoglobin in the plasma were determined using a solid-phase sandwich ELISA kit (MyBioSource, San Diego, CA, USA) according to the manufacturer's instructions. The level of the terminal complement complex (SC5b-9) was determined using a solid-phase sandwich ELISA kit (Quidel Corp., San Diego, CA, USA).

Statistical analysis. For the analysis of iTRAQ ratios (i.e., T2:T1 and T3:T1) of each identified protein, P-values were calculated using a one-sample t-test of averaged protein ratio against 1 to assess the validity of the alterations in protein expression $(10,11)$. Statistical comparisons were performed using the paired t-test or Wilcoxon signed-rank test followed by a post-hoc Bonferroni test to estimate significant changes in the iTRAQ ratios of several important proteins and the corresponding western blotting/ELISA data.

\section{Results}

Proteomic changes during TH after ROSC. Proteomic analysis identified 189 proteins having an FDR <5\%. Among those, 92 proteins identified in at least five of the nine samples had significant protein confidence $>99 \%$ ('used Protscore' $>2$ ). To demonstrate the abundance of proteins using fold changes and P-values, fold changes (T2/T1, T3/T1) were combined with their P-values, with the two vertical lines showing a fold change $=1.2$ and $=0.833$, respectively, and the horizontal line showing $\mathrm{P}<0.05$ (Fig. $2 \mathrm{~A}$ and $\mathrm{B}$ ). Acute phase proteins were significantly upregulated during both cooling (Fig. 2A) and rewarming (Fig. 2B). Conversely, complement proteins were not significantly upregulated during cooling and rewarming. Fifteen proteins demonstrated statistically significant alterations, including many upregulated proteins belonging to the acute-phase response (Table II). Unexpectedly, both hemoglobin subunit $\alpha$ and $\beta$ were significantly downregulated during TH.

Proteomic profiling using DAVID. Protein levels decreased or increased ( $<0.833$ fold or $>1.2$ fold, respectively) in at least five of the nine samples were identified and analyzed for gene enrichment $(10,15)$ and functional annotation using the DAVID software. Two GO terms, 'platelet degranulation' and 'acute-phase response', demonstrated the most statistically significant protein enrichment (Tables III and IV).

Western blotting and ELISA analysis. Both units of hemoglobin decreased in seven samples of patients who did not undergo transfusion (Fig. 3A and B). The difference was statistically significant. ELISA analysis corroborated this statistically significant downregulation of free hemoglobin induced by TH (Fig. 3C). Western blotting analysis confirmed 

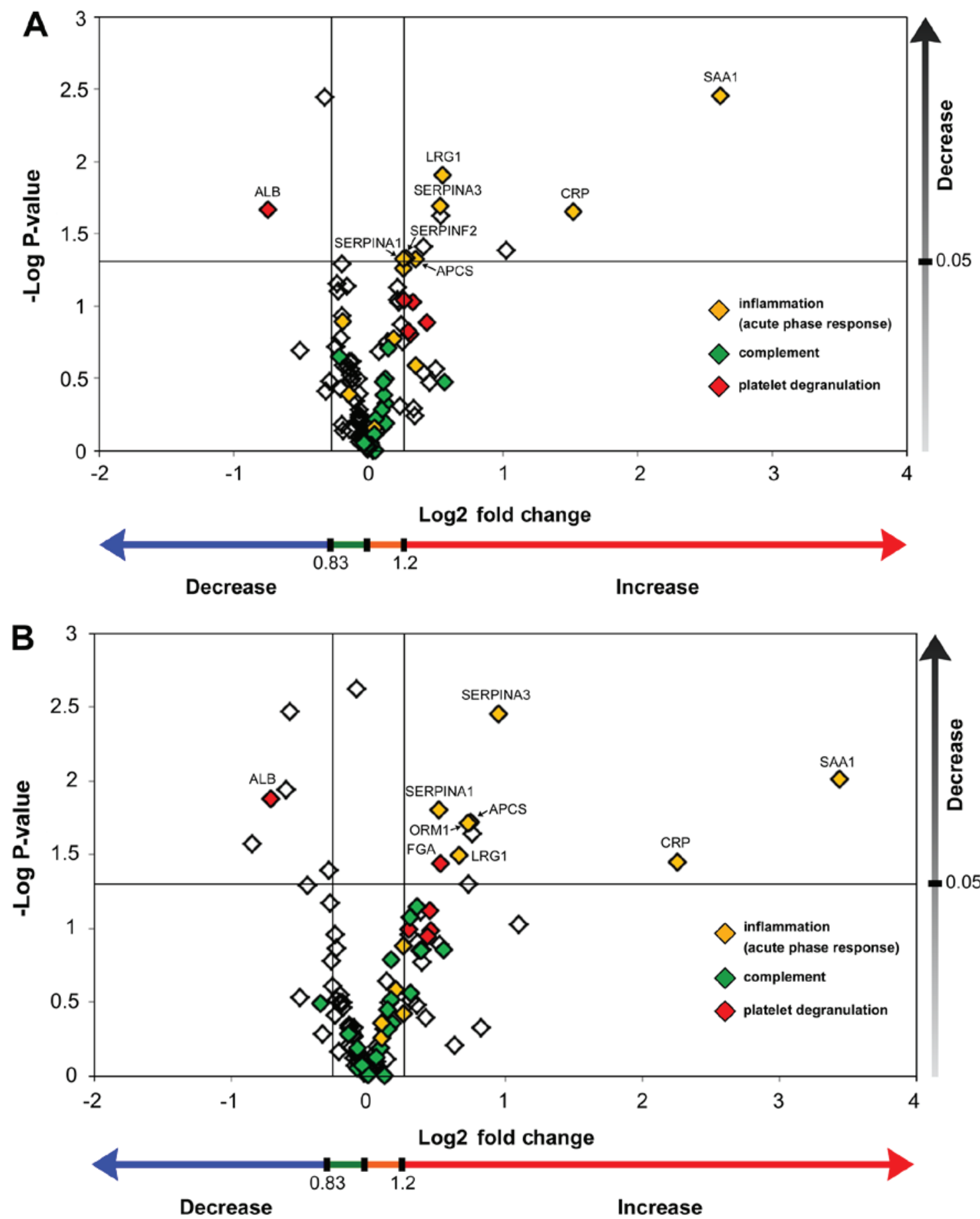

Figure 2. Scatter plot graph of the identified plasma proteins with statistical significance. (A) Samples were obtained after therapeutic hypothermia (T2/T1). (B) Samples were obtained after rewarming (T3/T1) of the resuscitated patients. Values are demonstrated by the log-transformed iTRAQ ratio and one-sample test P-values. Fold changes (T2/T1, T3/T1) $>1.2$ or $<0.833$ were defined as significant up- or down-regulation, respectively (demonstrated by the two vertical lines). P-values were calculated using a one-sample t-test of averaged protein ratio (T2/T1, T3/T1) against 1. P $<0.05$ denoted statistical significance (demonstrated by the horizontal line). T1, prior to cooling; T2, prior to rewarming; T3, immediately after rewarming; iTRAQ, isobaric tag for relative and absolute quantification.

the statistically significant upregulation of ApoC3 (Fig. 4) and the statistically significant downregulation of gelsolin at T3 $(\mathrm{T} 3 / \mathrm{T} 1=0.66 \pm 0.27, \mathrm{P}=0.039)$. Western blotting revealed that the levels of ApoA1 did not change significantly during $\mathrm{TH}$ ( $\mathrm{T} 3 / \mathrm{T} 1=0.87 \pm 0.16, \mathrm{P}=0.091)$. However, the levels of SC5b-9 decreased significantly $(\mathrm{P}=0.023)$ through cooling from $\mathrm{T} 1$ to $\mathrm{T} 2$ and subsequently increased slightly through rewarming from T2 to T3 (P=1.00) (Fig. 5).

\section{Discussion}

Ethical reasons prohibited the inclusion of a control group (i.e., ROSC patients after cardiac arrest without TH) in this study. Therefore, it was not possible to distinguish between hypothermia-induced changes and those occurring during the course of SIRS after cardiac arrest (16). To overcome this challenge, we utilized our serum proteome data previously 


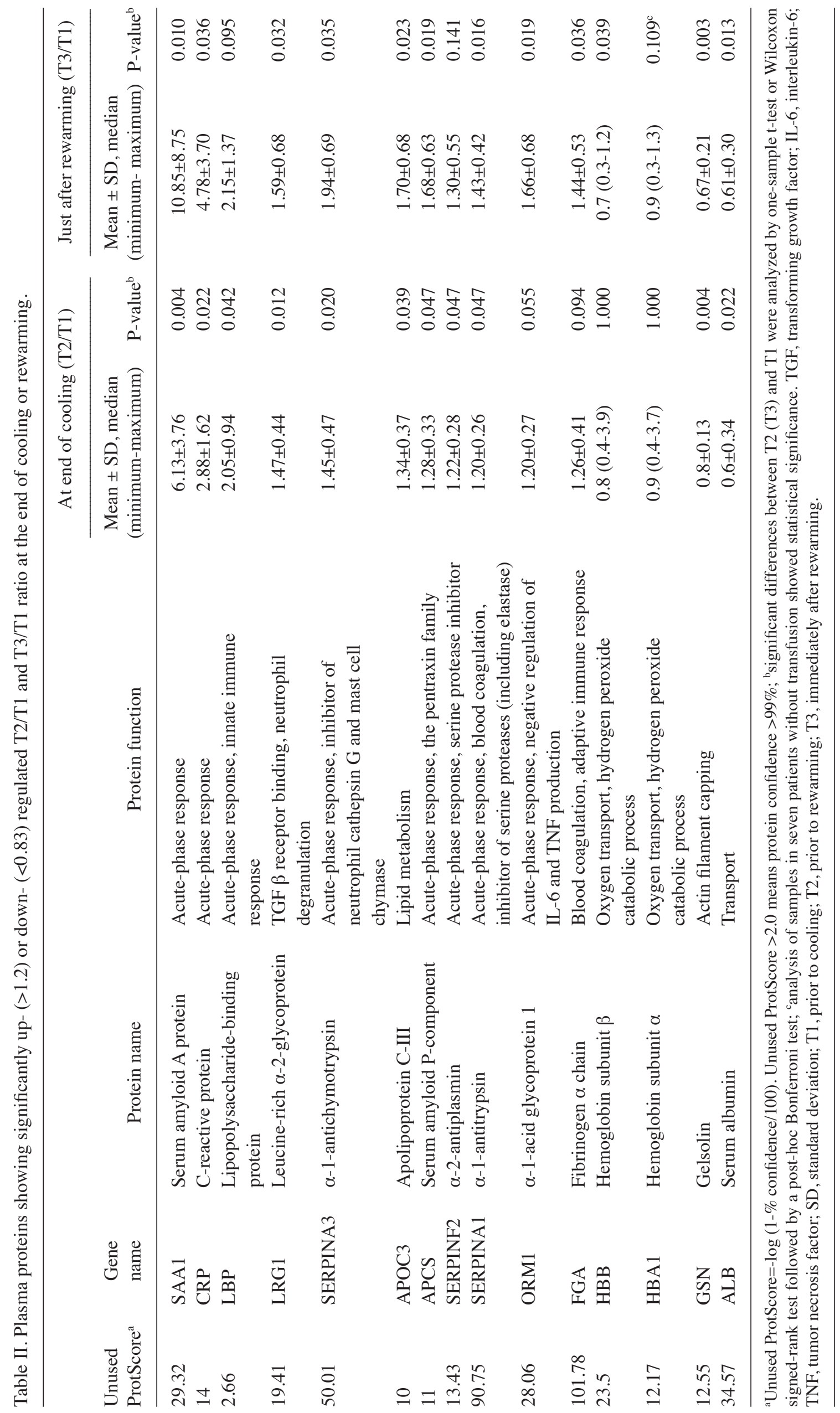


Table III. Top 10 Gene Ontology terms showing statistically significant protein enrichment for plasma samples taken from patients having therapeutic hypothermia during cooling.

\begin{tabular}{|c|c|c|c|c|}
\hline Gene Ontology term & $\begin{array}{c}\text { Number of } \\
\text { observed genes }\end{array}$ & P-value & $\begin{array}{l}\text { Benjamini's } \\
\text { correction }\end{array}$ & Genes \\
\hline Platelet degranulation & 11 & $1.6 \times 10^{-17}$ & $3.5 \times 10^{-15}$ & $\begin{array}{l}\text { ALB, FGA, FGB, FGG, FN1, ITIH3, ORM1, } \\
\text { PROS1, SERPINA1, SERPINA3, SERPINF2 }\end{array}$ \\
\hline Acute-phase response & 9 & $7.8 \times 10^{-17}$ & $1.2 \times 10^{-14}$ & $\begin{array}{l}\text { CRP, APCS, FN1, LBP, ORM1, SERPINA1, } \\
\text { SERPINA3, SERPINF2, SAA1 }\end{array}$ \\
\hline Fibrinolysis & 5 & $1.1 \times 10^{-8}$ & $7.8 \times 10^{-7}$ & FGA, FGB, FGG, PROS1, SERPINF2 \\
\hline $\begin{array}{l}\text { Negative regulation of } \\
\text { endopeptidase activity }\end{array}$ & 6 & $3.3 \times 10^{-7}$ & $1.8 \times 10^{-5}$ & $\begin{array}{l}\text { C4A, ITIH3, PROS1, SERPINA1, SERPINA3, } \\
\text { SERPINF2 }\end{array}$ \\
\hline Blood coagulation & 6 & $2.6 \times 10^{-6}$ & $1.2 \times 10^{-4}$ & FGA, FGB, FGG, HBB, PROS1, SERPINA1 \\
\hline $\begin{array}{l}\text { Blood coagulation, } \\
\text { fibrin clot formation }\end{array}$ & 3 & $8.9 \times 10^{-6}$ & $3.3 \times 10^{-4}$ & FGA, FGB, FGG \\
\hline Innate immune response & 7 & $1.1 \times 10^{-5}$ & $3.3 \times 10^{-4}$ & $\begin{array}{l}\text { APCS, C4A, FGA, FGB, LBP, PGLYRP2, } \\
\text { SAA1 }\end{array}$ \\
\hline Platelet aggregation & 4 & $1.7 \times 10^{-5}$ & $4.8 \times 10^{-4}$ & FGA, FGB, FGG, HBB \\
\hline $\begin{array}{l}\text { Positive regulation of } \\
\text { peptide hormone secretion }\end{array}$ & 3 & $4.2 \times 10^{-5}$ & $1.0 \times 10^{-3}$ & FGA, FGB, FGG \\
\hline Plasminogen activation & 3 & $5.3 \times 10^{-5}$ & $1.2 \times 10^{-3}$ & FGA, FGB, FGG \\
\hline
\end{tabular}

In the patients having therapeutic hypothermia, 22 proteins found in at least 5 found 9 samples with upregulation (>1.2-fold) or downregulation $(<0.83$-fold) during cooling were analyzed using DAVID software.

Table IV. Top 10 Gene Ontology terms showing statistically significant protein enrichment for plasma samples taken from patients having therapeutic hypothermia after rewarming.

\begin{tabular}{|c|c|c|c|c|}
\hline Gene Ontology term & $\begin{array}{l}\text { Number of } \\
\text { observed genes }\end{array}$ & P-value & $\begin{array}{l}\text { Benjamini's } \\
\text { correction }\end{array}$ & Genes \\
\hline Platelet degranulation & 10 & $3.7 \times 10^{-14}$ & $1.3 \times 10^{-11}$ & $\begin{array}{l}\text { ALB, FGA, FGB, FGG, ITIH3, ORM1, PROS1, } \\
\text { SERPINA1, SERPINA3, SERPINF2 }\end{array}$ \\
\hline Acute-phase response & 8 & $1.8 \times 10^{-13}$ & $3.2 \times 10^{-11}$ & $\begin{array}{l}\text { CRP, APCS, LBP, ORM1, SERPINA1, } \\
\text { SERPINA3, SERPINF2, SAA1 }\end{array}$ \\
\hline $\begin{array}{l}\text { Negative regulation of } \\
\text { endopeptidase activity }\end{array}$ & 8 & $6.7 \times 10^{-10}$ & $8.2 \times 10^{-8}$ & $\begin{array}{l}\text { AGT, C4A, ITIH3, PROS1, } \\
\text { SERPINA1, SERPINA3, SERPINF2, VTN }\end{array}$ \\
\hline Fibrinolysis & 5 & $3.1 \times 10^{-8}$ & $2.9 \times 10^{-6}$ & FGA, FGB, FGG, PROS1, SERPINF2 \\
\hline Innate immune response & 9 & $2.5 \times 10^{-7}$ & $1.8 \times 10^{-5}$ & $\begin{array}{l}\text { APCS, APOL1, C1R, C1S, C4A, FGA, FHB, } \\
\text { LBP, SAA1 }\end{array}$ \\
\hline Lipoprotein metabolism process & 5 & $3.8 \times 10^{-7}$ & $2.3 \times 10^{-5}$ & ALB, APOC2, APOC3, APOE, APOL1 \\
\hline Receptor-mediated endocytosis & 7 & $4.2 \times 10^{-7}$ & $2.2 \times 10^{-5}$ & $\begin{array}{l}\text { ALB, APOE, APOL1, HBA1, HBB, SAA1, } \\
\text { VTN }\end{array}$ \\
\hline Protein polymerization & 4 & $1.0 \times 10^{-6}$ & $4.8 \times 10^{-5}$ & FGA, FGB, FGG, VTN \\
\hline Blood coagulation & 6 & $9.9 \times 10^{-6}$ & $4.0 \times 10^{-4}$ & FGA, FGB, FGG, HBB, PROS1, SERPINA1 \\
\hline $\begin{array}{l}\text { Regulation of complement } \\
\text { activation }\end{array}$ & 4 & $1.5 \times 10^{-5}$ & $5.4 \times 10^{-4}$ & C4A, C9, PROS1, VTN \\
\hline
\end{tabular}

In the patients having therapeutic hypothermia, 28 proteins found in at least 5 found 9 samples with upregulation ( $>1.2$-fold) or downregulation $(<0.83$-fold $)$ after rewarming were analyzed using DAVID software.

reported in a study (17) as 'control'. The previous and present studies were conducting using an identical methodology and analytical approach. The proteomic data obtained in the present study were compared with the serum proteome data obtained from five patients (average age: 73 years; four males, one female) pre- and post-operatively (average of 13.1 days after 
A

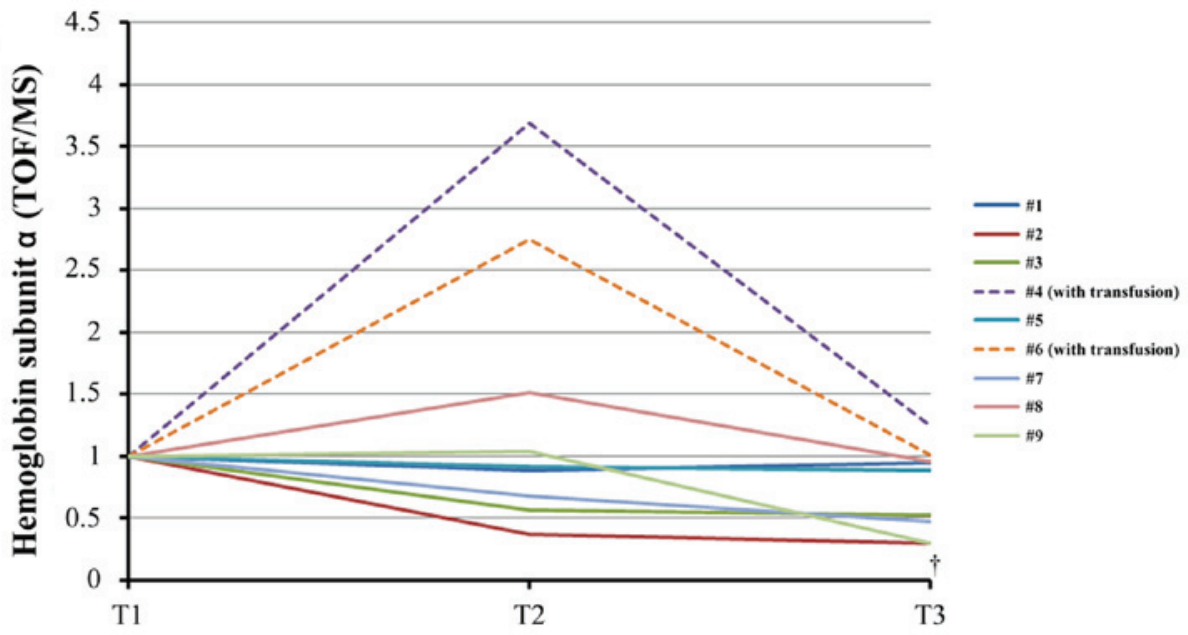

B

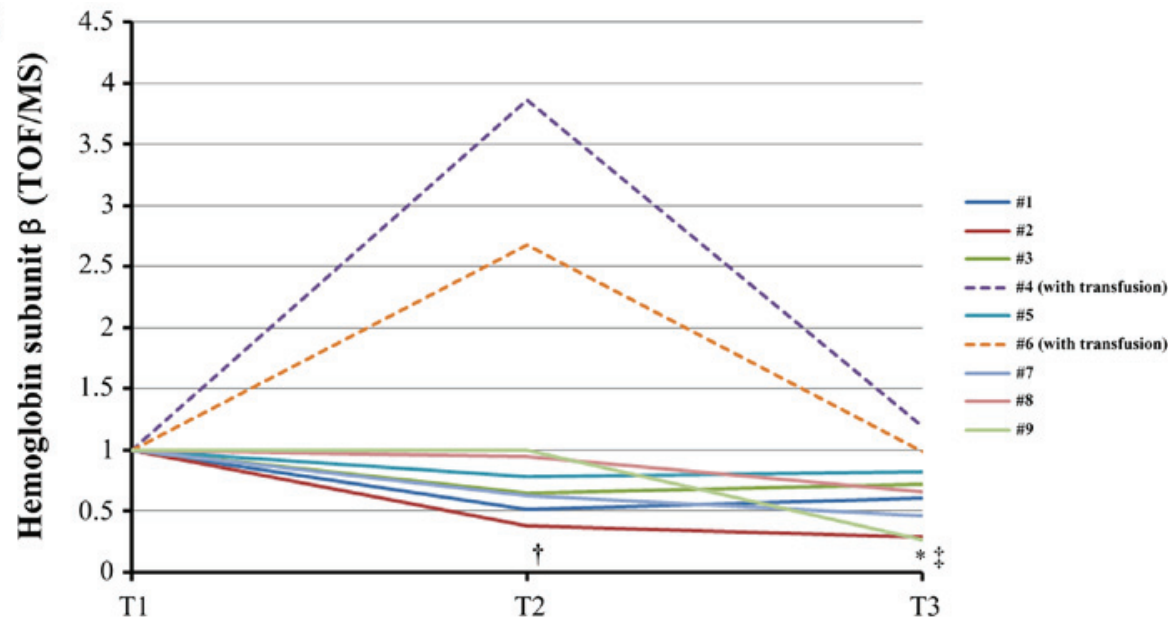

C

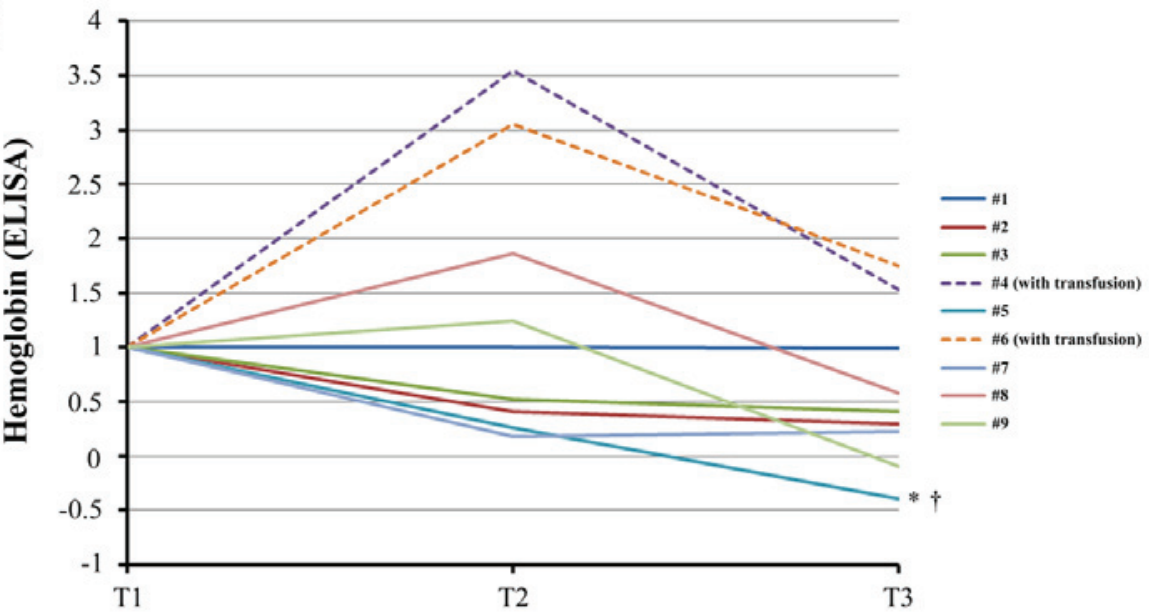

Figure 3. Changes of plasma free hemoglobin levels during therapeutic hypothermia. (A) iTRAQ ratio alterations in the levels of hemoglobin subunit $\alpha$ during TH. $\dagger$, analysis excluding patients who received transfusion (\#4, \#6), $\mathrm{P}=0.031$ between $\mathrm{T} 1$ and $\mathrm{T} 3$ using the paired t-test with post-hoc analysis using the Bonferroni method. (B) iTRAQ ratio alterations in the levels of hemoglobin subunit $\beta$ levels during TH. "P=0.039 between T1 and T3 using the Wilcoxon signed-rank test with post-hoc analysis using the Bonferroni method. $\uparrow \mathrm{P}=0.025$ between $\mathrm{T} 1$ and $\mathrm{T} 2$ in analysis excluding patients who received transfusion (\#4, \#6) using the paired t-test with post-hoc analysis by the Bonferroni method. ${ }^{\mathrm{P}} \mathrm{P}=0.003$ between $\mathrm{T} 1$ and $\mathrm{T} 3$ in analysis excluding patients who received transfusion (\#4, \#6) using the paired t-test with post-hoc analysis by the Bonferroni method. (C) Alterations in the levels of free hemoglobin measured by enzyme-linked immunosorbent assay (ELISA) during TH. " $\mathrm{P}=0.042$ between $\mathrm{T} 2$ and $\mathrm{T} 3$ using the paired $\mathrm{t}$-test with post-hoc analysis using the Bonferroni method. ${ }^{\dagger}$ Analysis excluding patients who received transfusion (\#4,\#6), $\mathrm{P}=0.047$ between $\mathrm{T} 1$ and $\mathrm{T} 3$ using the Wilcoxon signed-rank test with post-hoc analysis using the Bonferroni method. T1, prior to cooling; T2, prior to rewarming; T3, immediately after rewarming; iTRAQ, isobaric tag for relative and absolute quantification; TOF, time-of-flight; MS, mass spectrometry.

cardiac surgery). Cardiac surgery is commonly accompanied by ischemic reperfusion injury. Thus, SIRS inevitably occurs post-operatively and may lead to multiple organ dysfunction or death (18-21). This fact prompted us to use the proteomic data 
$\mathrm{T} 1 \quad \mathrm{~T} 2 \quad \mathrm{~T} 3$
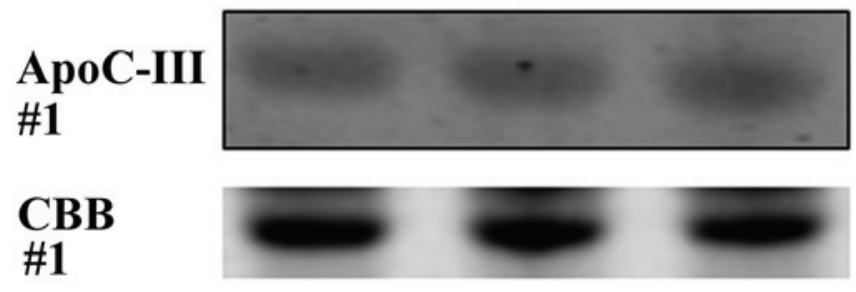

\begin{tabular}{|c|r|r|r|}
\hline & \multicolumn{1}{|c|}{ T1 } & \multicolumn{1}{|c|}{ T2 } & \multicolumn{1}{c|}{ T3 } \\
\hline ApoC-III & 0.86 & 0.94 & 1 \\
\hline CBB & 13.62 & 12.43 & 11.19 \\
\hline ApoC-III/CBB & 0.063 & 0.076 & 0.089 \\
\hline Ratio & 1.000 & 1.198 & 1.415 \\
\hline
\end{tabular}

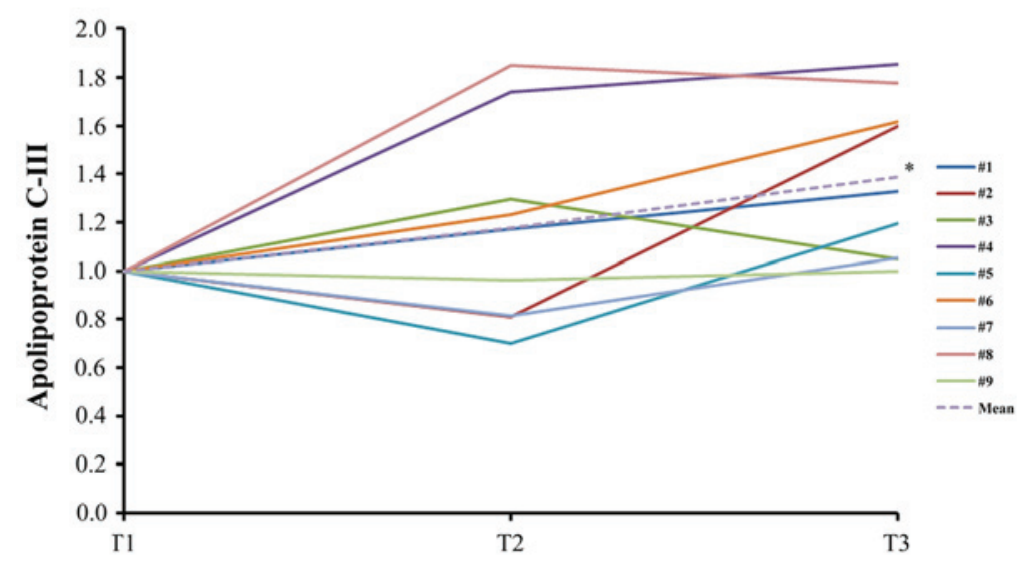

Figure 4. Representative images and relative intensities from the western blot analysis of ApoC3. As an internal loading control, non-specific proteins stained with $\mathrm{CBB}$ are shown in the lower panel. Data from triplicate experiments were analyzed to calculate the average values. ${ }^{*} \mathrm{P}=0.046$ between $\mathrm{T} 1$ and $\mathrm{T} 3 \mathrm{using}$ the paired t-test with post-hoc analysis using the Bonferroni method. ApoC3, apolipoprotein C3; CBB, Coomassie Brilliant Blue; T1, prior to cooling; T2, prior to rewarming; T3, immediately after rewarming.

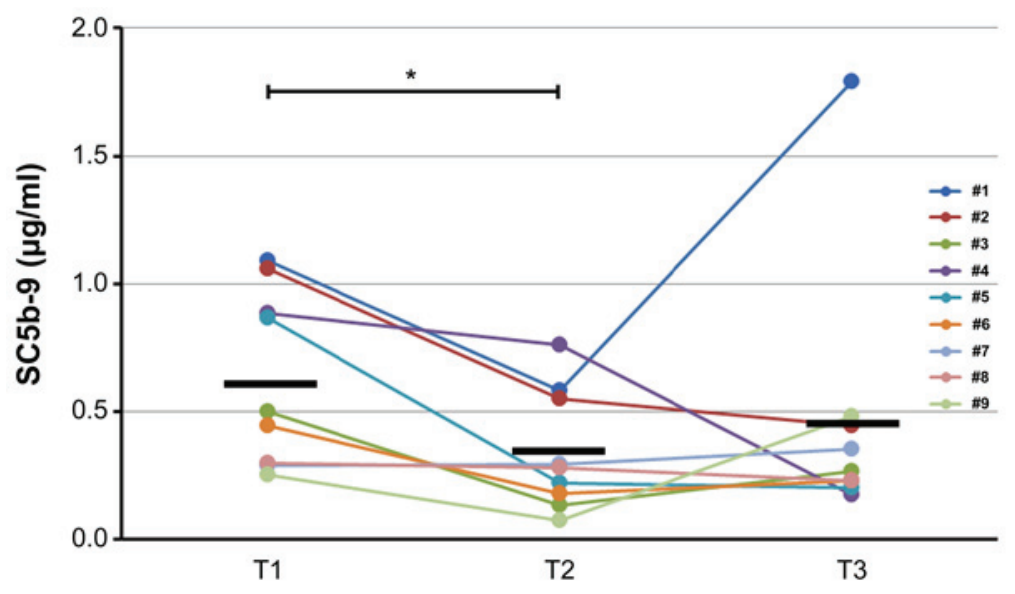

Figure 5. ELISA analysis of the levels of the terminal complement complex (SC5b-9) during therapeutic hypothermia after return of spontaneous circulation. ${ }^{*} \mathrm{P}=0.023$ between $\mathrm{T} 1$ and $\mathrm{T} 2$ using the Wilcoxon signed-rank test with post-hoc analysis by the Bonferroni method. The black horizontal lines in each time point indicate the mean values of SC5b-9.

in the post-cardiac surgery group as a possible surrogate of the control group, namely ROSC patients after cardiac arrest not undergoing $\mathrm{TH}$.

Although many proteins belonging to the acute-phase response were upregulated in a similar manner in both groups, proteins related to the complement system were not upregulated in the TH after ROSC group compared with those in the post-cardiac surgery group (Fig. 6). For example, serum amyloid A1 (SAA1) is a major acute-phase protein with cytokine-like activity during inflammation (22). 


\section{Upregulated proteins $(>1 \cdot 2)$ identified in more than half samples}

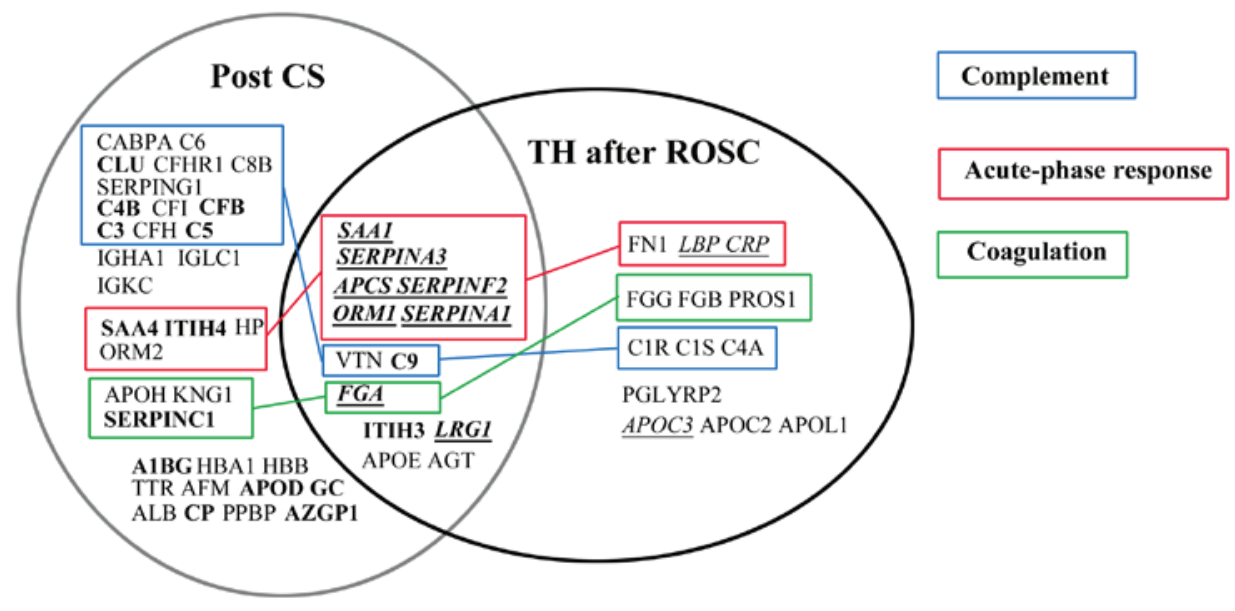

Downregulated proteins $(<0.83)$ identified in more than half samples
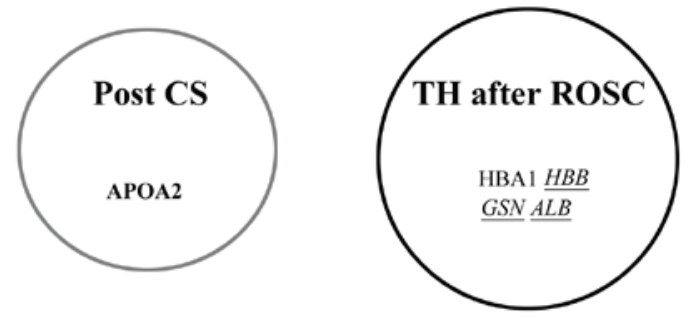

Figure 6. Comparison of plasma/serum proteomic data between patients undergoing TH after ROSC and those who underwent cardiac surgery. Proteomic data were obtained (17). Bold, proteins with statistically significant $(\mathrm{P}<0.05)$ upregulation or downregulation in samples of post-CS patients; Italics with underline, proteins with statistically significant $(\mathrm{P}<0.05)$ upregulation or downregulation in samples of patients undergoing TH after ROSC. Proteins were classified into 'complement', 'acute-phase response', and 'coagulation' according to their principal Gene Ontology term in the Uniprot database. Post CS, post-cardiac surgery; TH, therapeutic hypothermia; ROSC, return of spontaneous circulation.

SAA1 and five other proteins of the acute-phase response were upregulated in a similar manner in both the TH after ROSC and post-cardiac surgery groups. In agreement with recent reports $(6,23-25)$, these findings imply that $\mathrm{TH}$ does not reduce the acute-phase response after ROSC and that systemic inflammation is not influenced by TTM at $33^{\circ} \mathrm{C}$ or $36^{\circ} \mathrm{C}(6)$. However, there are numerous studies supporting the hypothermic suppression of inflammation (26). These results suggest that a lower temperature (i.e., $<33^{\circ} \mathrm{C}$ ) may decrease the inflammatory response (6). The systemic inflammatory response and apoptosis are thought to continue for several days after reperfusion or traumatic injuries. Thus, a prolonged duration of hypothermia (e.g., 72 vs. 24 h) may be more beneficial to patients $(24,26)$.

According to the analysis performed using the DAVID software, platelet degranulation was the most enriched GO term in the TH after ROSC patients. Platelets contain $\alpha$ granule contents, dense granule contents, and lysosomes (27). These include adhesion molecules, chemokines, cytokines, coagulation factors, and immunological molecules (28). Platelet degranulation is induced by several receptor signaling pathways including platelet pattern-recognition receptor signaling. The latter is triggered by pathogen-associated molecular patterns (PAMPs) or damage-associated molecular patterns (DAMPs) (28). DAMPs were reported to increase at days 0 and 1 after ROSC (29). The resultant platelet activation results in inflammation and thrombosis, leading to the interaction of both processes $(30,31)$.
Although numerous complement proteins were upregulated in the post-cardiac surgery group, this phenomenon did not occur in the TH after ROSC group (Fig. 6). Both findings were consistent with the bioinformatic analysis (Tables III-V). These suggest that TH may suppress the complement activation in ROSC patients after cardiac arrest. In addition, this finding was confirmed by the decreased levels of soluble C5b-9 (membrane attack complex=MAC) during TH (Fig. 5), also consistent with the findings of previous studies $(10,24,25,32)$. Complement activation is involved in the pathogenesis of ischemic reperfusion injury and SIRS (33), and SC5b-9 is a good predictor of prognosis in myocardial/renal ischemia $(34,35)$. Collectively, these findings indicate that the therapeutic effect of TH may be the result, at least partially, of the suppression of complement activation.

Free (extracellular) hemoglobin may act as a peroxidase in the presence of hydrogen peroxide $(36,37)$ and lead to the consumption of nitric oxide and vasoconstriction (38), causing acute kidney and lung injury $(39,40)$. This is the first study to demonstrate that the levels of free hemoglobin decreased during the cooling and rewarming phases after ROSC. PCAS shares numerous features with sepsis, such as elevated levels of cytokines (4). In the early stage of sepsis, circulating levels of hemoglobin subunit $\beta$ were found to be significantly higher in sepsis patients compared with those reported in the control group (41). These findings suggest that PCAS may be naturally accompanied by an increase in the levels of hemoglobin subunit $\beta$ that may be 
Table V. Top 10 Gene Ontology terms showing statistically significant protein enrichment for serum samples obtained from patients having cardiac surgery.

\begin{tabular}{|c|c|c|c|c|}
\hline Gene Ontology term & $\begin{array}{c}\text { Number of } \\
\text { observed genes }\end{array}$ & P-value & $\begin{array}{l}\text { Benjamini's } \\
\text { correction }\end{array}$ & Genes \\
\hline $\begin{array}{l}\text { Complement activation, } \\
\text { classical pathway }\end{array}$ & 17 & $2.5 \times 10^{-24}$ & $1.0 \times 10^{-21}$ & $\begin{array}{l}\text { CLU, C3, C4B, C5, C6, C8B, C9, C4BPA, } \\
\text { CFI, IGHA1, IGKC, IGKV3-20, IGKV3D-11, } \\
\text { IGKV4-1, IGLC1, IGLV3-21, SERPING1 }\end{array}$ \\
\hline Complement activation & 15 & $2.7 \times 10^{-21}$ & $5.6 \times 10^{-19}$ & $\begin{array}{l}\text { CLU, C3, C4B, C5, C6, C8B, CFB, CFHR1, } \\
\text { CFH, IGKC, IGKV3-20, IGKV3D-11, } \\
\text { IGKV4-1, IGLC1, IGLV3-21 }\end{array}$ \\
\hline Platelet degranulation & 15 & $3.3 \times 10^{-20}$ & $4.6 \times 10^{-18}$ & $\begin{array}{l}\text { ALB, A1BG, APOH, CLU, FGA, ITIH3, ITIH4, } \\
\text { KNG1, ORM1, ORM2, PPBP, SERPINA1, } \\
\text { SERPINA3, SERPINF2, SERPING1 }\end{array}$ \\
\hline $\begin{array}{l}\text { Regulation of complement } \\
\text { activation }\end{array}$ & 11 & $6.0 \times 10^{-19}$ & $6.3 \times 10^{-17}$ & $\begin{array}{l}\text { C3, C4B, C5, C6, C8B, C9, C4BPA, CFB, CFH, } \\
\text { CFI, VTN }\end{array}$ \\
\hline Receptor-mediated endocytosis & 15 & $1.6 \times 10^{-16}$ & $9.3 \times 10^{-15}$ & $\begin{array}{l}\text { ALB, APOE, CFI, HP, HBA1, HBB, IGHA1, } \\
\text { IGKC, IGKV3-20, IGKV3D-11, IGKV4-1, } \\
\text { IGLC1, IGKV3-21, SAA1, VTN }\end{array}$ \\
\hline $\begin{array}{l}\text { Negative regulation of } \\
\text { endopeptidase activity }\end{array}$ & 13 & $1.1 \times 10^{-15}$ & $7.8 \times 10^{-14}$ & $\begin{array}{l}\text { AGT, C3, C4B, C5, ITIH3, ITIH4, KNG1, } \\
\text { SERPINA1, SERPINA3, SERPINC1, } \\
\text { SERPINF2, SERPING1, VTN }\end{array}$ \\
\hline Acute-phase response & 12 & $1.7 \times 10^{-15}$ & $1.0 \times 10^{-13}$ & $\begin{array}{l}\text { APCS, HP, ITIH4, ORM1, ORM2, SERPINA1, } \\
\text { SERPINA3, SERPINF2, SAA1, SAA4 }\end{array}$ \\
\hline $\begin{array}{l}\text { Complement activation, } \\
\text { alternative pathway }\end{array}$ & 6 & $2.4 \times 10^{-10}$ & $1.3 \times 10^{-8}$ & C3, C5, C8B, C9, CFB, CFH \\
\hline Immune response & 12 & $3.3 \times 10^{-8}$ & $1.6 \times 10^{-6}$ & $\begin{array}{l}\text { C3 C8B C9 IGHA1 IGKC IGKV3-20 } \\
\text { IGKV3D-11 IGKV4-1 IGLC1 IGLV3-21 PPBP } \\
\text { VTN }\end{array}$ \\
\hline Innate immune response & 12 & $4.2 \times 10^{-8}$ & $1.7 \times 10^{-6}$ & $\begin{array}{l}\text { APCS CLU C4B C6 C4BPA CFI FGA IGHA1 } \\
\text { IGKC1 IGLC1SERPING1 SAA1 }\end{array}$ \\
\hline
\end{tabular}

In the patients having aortic valve replacement, 51 proteins found in at least 3 found 5 samples with upregulation ( $>1.2$-fold) or downregulation $(<0.83$-fold $)$ were analyzed by the DAVID software. Proteomic data was obtained (17).

suppressed by TH. This reduction of free hemoglobin may be the consequence of reduced hemolysis and/or augmented scavenging reaction of hemoglobin. Normal erythrocytes were shown to be lysed by the formation of the MAC of complement C5b-9 following activation of the complement system by zymosan (42). This activation has been reported to decrease at temperatures $<37^{\circ} \mathrm{C}(42)$. Thus, hypothermia may suppress the activation of the complement system and thereby suppress hemolysis.

The hemoglobin scavenging system is known as the haptoglobin-CD163-heme oxygenase-1 pathway and hemopexin-CD91-HO pathway $(43,44)$. It is well known that increased levels of free hemoglobin in the plasma accompany the decreased levels of haptoglobin, as shown in cardiac surgery (45). However, the present plasma proteomic analysis did not demonstrate any significant changes in the abundance of haptoglobin $(\mathrm{T} 3 / \mathrm{T} 1=1.19 \pm 0.35, \mathrm{P}=0.132)$ and hemopexin ( $\mathrm{T} 3 / \mathrm{T} 1=1.01 \pm 0.30, \mathrm{P}=0.931)$ during $\mathrm{TH}$ after ROSC. Based on this evidence, it is inferred that unknown mechanisms may be involved in the scavenging of free hemoglobin. Although
ApoC3 was significantly upregulated during cooling and rewarming, there was no evidence regarding the interaction between ApoC3 and cell-free hemoglobin. However, lipid-free ApoA1 acts as an antioxidant against cell-free hemoglobin and may facilitate receptor-mediated endocytosis of free hemoglobin via a scavenger receptor class B type 1 (SR-B1) or an ApoA1 receptor (46). Furthermore, in an animal model, small fragments of apolipoprotein E reduced the levels of free hemoglobin via the ubiquitous heparin sulfate proteoglycan-associated pathway (47). During the acute-phase response, marked elevation in the levels of SAA protein in the plasma causes high-density lipoprotein (HDL) remodeling, with the newly synthesized SAA1 and SAA2 displacing ApoA1 and becoming an apolipoprotein of HDL $(22,48)$. This indicates that the increased levels of SAA1/2 may increase those of free ApoA1 during the acute-phase response. Although ApoA1 was not upregulated during $\mathrm{TH}$, it is uncertain whether the levels of free ApoA1 may be altered during treatment.

The limitations of the present study include the absence of a control group and the small sample size. Therefore, 
further studies involving larger sample sizes and, if possible, a control group are necessary to confirm the present findings.

In conclusion, plasma proteomic analysis demonstrated that the abundance of complement proteins did not change and the levels of SC5b-9 and free hemoglobin decreased in patients undergoing TH after ROSC. However, proteins belonging to the acute-phase response were upregulated during $\mathrm{TH}$. These novel findings may contribute to the current knowledge regarding $\mathrm{TH}$ after ROSC.

\section{Acknowledgements}

The authors would like to thank Ms. Yasuko Sonoyama (Division of Thoracic and Cardiovascular Surgery, Department of Surgery, Shimane University Faculty of Medicine, Izumo, Japan) for the sample collection and management.

\section{Funding}

The present study was supported by the Japan Society for the Promotion of Science KAKENHI (grant no. JP23659845).

\section{Availability of data and materials}

The datasets used and/or analyzed during the current study are available from the corresponding author on reasonable request.

\section{Authors' contributions}

TO conceived and designed the present study. RI, TN and KS acquired blood samples and clinical data. AY performed the proteomic and western blot/ELISA analyses. TO and KM analyzed the data. TO wrote the manuscript. All authors read and approved the final manuscript.

\section{Ethics approval and consent to participate}

This prospective, cohort study was approved by the Ethics Committee of Shimane University Faculty of Medicine and Shimane Prefectural Central Hospital (Izumo, Japan). Written informed consent was provided by the relatives of the patients.

\section{Patient consent for publication}

Not applicable.

\section{Competing interests}

The authors declare that they have no competing interests.

\section{References}

1. Geocadin RG, Wijdicks E, Armstrong MJ, Damian M, Mayer SA, Ornato JP, Rabinstein A, Suarez JI, Torbey MT, Dubinsky RM and Lazarou J: Practice guideline summary: Reducing brain injury following cardiopulmonary resuscitation. Report of the guideline development, dissemination and implementation subcommittee of the American academy of neurology. Neurology 88: 1-9, 2017.
2. Callaway CW, Donnino MW, Fink EL, Geocadin RG, Golan E, Kern KB, Leary M, Meurer WJ, Peberdy MA, Thompson TM and Zimmerman JL: Part 8: Post-cardiac arrest care. 2015 American Heart Association guidelines updates for cardiopulmonary resuscitation and emergency cardiovascular care. Circulation 132 (18 Suppl 1): S465-S482, 2015.

3. Bro-Jeppesen J, Kjaergaard J, Wanscher M, Nielsen N, Friberg H, Mjerre M and Hassager C: Systemic inflammatory response and potential prognostic implications after out-of-hospital cardiac arrest: A study of the target temperature management trial. Crit Care Med 43: 1223-1232, 2015.

4. Nolan JP, Neumar RW, Adrie C, Aibiki M, Berg RA, Bottinger BW, Callaway C, Clark RS, Geocadin RG, Jauch EC, et al: Post-cardiac syndrome: Epidemiology, pathophysiology, treatment and prognostication. A scientific statement from the international liaison committee on resuscitation; the American heart association emergency cardiovascular care committee; the council on cardiovascular surgery and anesthesia; the council on cardiopulmonary, perioperative, and critical care; the council on clinical cardiology; the council on stroke. Resuscitation 79: 350-379, 2008.

5. Nakashima R, Hifumi T, Kawakita K, Okazaki T, Egawa S, Inoue A, Seo R, Inagaki N and Kuroda Y: Critical care management focused on optimizing brain function after cardiac arrest. Circ J 81: 427-439, 2017

6. Bro-Jeppesen J, Kjaergaard J, Wanscher M, Nielsen N, Friberg $\mathrm{H}$, Bjerre $\mathrm{M}$ and Hassager $\mathrm{C}$ : The inflammatory response after out-of-hospital cardiac arrest is not modified by targeted temperature management at $33^{\circ} \mathrm{C}$ or $36^{\circ} \mathrm{C}$. Resuscitation 85 : 1480-1487, 2014

7. Adrie C, Adib-Conquy M, Laurent I, Monchi M, Vinsonneau C, Fitting C, Fraisse F, Dinh-Xuan T, Carli P, Spaulding C, et al: Successful cardiopulmonary resuscitation after cardiac arrest as a 'sepsis-like' syndrome. Circulation 106: 562-1568, 2002.

8. Skibsted S, Bhasin MK, Aird WC and Shapiro NI: Bench-to bedside review: Future novel diagnosis for sepsis-a systems biology approach. Crit Care 17: 231, 2013.

9. Wu L, Candille SI, Choi Y, Xie D, Jian L, Li-Pook-Than J, Tang $\mathrm{H}$ and Snyder M: Variation and genetic control of protein abundance in humans. Nature 499: 79-82, 2013.

10. Oda T, Yamaguchi A, Yokoyama M, Shimizu K, Toyota K, Nikai T and Matsumoto K: Plasma proteomic changes during hypothermic and normothermic cardiopulmonary bypass in aortic surgeries. Int J Mol Med 34: 947-956, 2014.

11. Oda T, Yamaguchi A, Shimizu K, Nikai T and Matsumoto K: Does the rewarmed heart restore the myocardial proteome to that of the precooled state? Circ J 79: 2648-2658, 2015.

12. Huang DW, Sherman BT and Lempicki RA: Bioinformatics enrichment tools: Paths toward the comprehensive functional analysis of large gene lists. Nucleic Acids Res 37: 1-13, 2009.

13. Huang da W, Sherman BT and Lempicki RA: Systematic and integrative analysis of large gene lists using DAVID bioinformatics resources. Nat Prot 4: 44-57, 2009.

14. Ashburner M, Ball CA, Blake JA, Botstein D, Butler H, Cherry JM, Davis AP, Dolinski K, Dwight SS, Eppig JT, et al: The gene ontology consortium. gene ontology: Tool for the unification of biology. Nature Genet 25: 25-29, 2000.

15. Lancaster TS, Jefferson SJ, Hunter JC, Lopez V, Van Eyk JE, Lakatta EG and Korzick DH: Quantitative proteomic analysis reveals novel mitochondrial targets of estrogen deficiency in the aged female rat heart. Physiol Genomics 44: 957-969, 2012.

16. Beurskens CJ and Jeffermans NP: Changes in the inflammatory response following cardiac arrest: A matter of ischemia/reperfusion or induced hypothermia? Crit Care Med 40: 3105-3106, 2012.

17. Satoh H, Yamada K, Maniwa T, Oda T and Matsumoto K: Monitoring of serial presurgical and postsurgical changes in the serum proteome in a series of patients with calcific aortic stenosis. Dis Markers 2015: 69412011, 2015.

18. Hall R, Smith MS and Rocker G: The systemic inflammatory response to cardiopulmonary bypass: Pathophysiological, therapeutic and pharmacological considerations. Anesth Analg 85: 766-782, 1997

19. Kouchoukos NT, Blackstone EH and Hanley FL and Kirklin JK: Hypothermia, circulatory arrest and cardiopulmonary bypass. In: Cardiac surgery. Fourth Edition. Kouchoukos NT, Blackstone EH, Hanley FL, Kirklin JK (eds), ELSEVIER, Philadelphia, pp67-132, 2012.

20. Stoppelkamp S, Veseli K, Stang K, Schlensak C, Wendel HP and Walker T: Identification of predictive early biomarkers for sterile-SIRS after cardiovascular surgery. PLOS One 10: e0135527, 2015. 
21. Zakkar M, Taylor $\mathrm{K}$ and Hornick PI: Immune system and inflammatory response to cardiopulmonary bypass. In: Cardiopulmonary bypass: Principles and practice. 3rd edition. Gravlee GP, Davis RF, Stammers AH and Ungerleider RM (eds) Wolters Kluwer/Lippincott Williams \& Wilkins, Philadelphia, PA, pp321-337, 2008.

22. Ye RD and Sun L: Emerging functions of serum amyloid A in inflammation. J Leukoc Biol 98: 923-929, 2015.

23. Bisschops LL, Hoedemaekers CW, Mollnes TE and van der Hoeven JG: Rewarming after hypothermia after cardiac arrest shifts the inflammatory balance. Crit Care Med 40: 1136-1142, 2012.

24. Bisschops LL, van der Hoeven JG, Mollnes TE and Hoedemaekers CW: Seventy-two hours of mild hypothermia after cardiac arrest is associated with a lowered inflammatory response during rewarming in a prospective observational study. Crit Care 18: 546, 2014

25. Beurskens CJ, Horn J, de Boer AM, Schultz MJ, van Leeuwen EM, Vroom MB and Jeffermans NP: Cardiac arrest patients have an impaired response, which is not influenced by induced hypothermia. Crit Care 18: R162, 2014.

26. Polderman KH: Mechanisms of action, physiological effects, and complications of hypothermia. Crit Care Med 37 (7 Suppl): S186-S202, 2009.

27. Reed GL: Platelet secretory mechanisms. Semin Thromb Hemost 30: 441-450, 2004

28. Estevez B and Du X: New concepts and mechanisms of platelet activation signaling. Physiology (Bethesda) 32: 162-177, 2017

29. Timmermans K, Kox M, Gerretsen J, Peters E, Scheffer GJ, van der Hoeven JG, Pickkers P and Hoedemaekers CW: The involvement of danger-associated molecular patterns in the development of immunoparalysis in cardiac arrest patients. Crit Care Med 43: 2332-2338, 2015.

30. Esmon CT: Crosstalk between inflammation and thrombosis. Maturitas 61: 122-131, 2008

31. Opal SM: Interactions between coagulation and inflammation. Scand J Infect Dis 35: 545-554, 2003.

32. Gong P, Zhao H, Hua R, Zhang M, Tang Z, Mei X, Cui J and Li C: Mild hypothermia inhibits systemic and cerebral complement activation in a swine model of cardiac arrest. J Cereb Blood Flow Metab 35: 1289-1295, 2015.

33. Elvington A, Atkinson C, Zhu H, Yu J, Takahashi K, Stahl GL, Kindy MS and Tomlinson S: The alternative complement pathway propagates inflammation and injury in murine ischemic stroke. J Immunol 189: 4640-4647, 2012.

34. Lindberg S, Pedersen SH, Mogelvang R, Galatius S, Flyvbjerg A, Jensen JS and Bjerre M: Soluble form of membrane attack complex independently predicts mortality and cardiovascular events in patients with ST-elevation myocardial infarction treated with primary percutaneous coronary intervention. Am Heart J 164: 786-792, 2012.

35. Kotimaa J, Van del Pol P, Leijtens S, Klar-Mohammad N, Schilders G, Daha MR, Rutjes H and van Kooten C: Functional assessment of rat complement pathway activities and quantification of soluble C5b-9 in an experimental model of renal ischemia/reperfusion injury. J Immunol Methods 412: 14-23, 2014.

36. Gutteridge JM: Iron promoters of the Fenton reaction and lipid peroxidation can be released from haemoglobin by peroxides. FEBS Lett 201: 291-295, 1986.
37. Kapralov A, Vlasova II, Feng W, Maeda A, Walson K, Tyurin VA, Huang Z, Aneja RK, Carcillo J, Bayir H, et al: Peroxidase activity of hemoglobin-haptoglobin complexes: covalent aggregation and oxidative stress in plasma and macrophages. J Biol Chem 284: 30395-30407, 2009.

38. Meyer C, Heiss C, Drexhage C, Kehmeier ES, Balzer J, Mühfeld A, Merx MW, Lauer T, Kühl H, Floege J, et al: Hemodialysis-induced release of hemoglobin limits nitric oxide bioavailability and impairs vascular function. J Am Coll Cardiol 55: 454-459, 2010.

39. Shaver CM, Upchurch CP, Janz DR, Grove BS, Putz ND, Wickersham NE, Dikalov SI, Ware LB and Bastarache JA: Cell-free hemoglobin: A novel mediator of acute lung injury. Am J Physiol Lung Cell Mol Physiol 310: L532-L541, 2016.

40. O'Neal JB, Shaw AD and Billings FT IV: Acute kidney injury following cardiac surgery: Current understanding and future directions. Crit Care 20: 187, 2016.

41. Yoo H, Ku SK, Kim SW and Bae J: Early diagnosis of sepsis using serum hemoglobin subunit beta. Inflammation 38: 394-399, 2015 .

42. Kitamura H, Nagano A and Kitano E: Hemolysis of normal human erythrocytes by autologous serum complement. Int Arch Allergy Immunol 100: 209-214, 1993.

43. Kristiansen M, Graversen JH, Jacobsen C, Sonne O, Hoffman HJ, Law SA and Moestrup SK: Identification of the hemoglobin scavenger receptor. Nature 409: 198-201, 2001.

44. Thomsen JH, Etzerodt A, Svendsen P and Moestrup SK: The haptoglobin-CD163-heme oxygenase-1 pathway for hemoglobin scavenging. Oxid Med Cell Longev 2013: 523652, 2013.

45. Vermeulen Windsant IC, de Wit NC, Sertorio JT, van Bijnen AA, Ganushchak YM, Heijmans JH, Tanus-Santos JE, Jacobs MJ, Maessen JG and Buurman WA: Hemolysis during cardiac surgery is associated with increased intravascular nitric oxide consumption and perioperative kidney and intestinal tissue damage. Front Physiol 5: 340, 2014

46. Du R, Winarsih I, Ho B and Ding JL: Lipid-free apolipoprotein A-I exerts an antioxidant role against cell-free hemoglobin. Am J Clin Exp Immunol 1: 33-48, 2012.

47. Hanson MS, Xu H, Flewelen TC, Holzhauer SL, Retherford D, Jones DW, Frei AC, Pritchard KA Jr, Hillery CA, Hogg N and Wandersee NJ: A novel hemoglobin-binding peptide reduces cell-free hemoglobin in murine hemolytic anemia. Am J Physiol heart Circ Physiol 304: H328-H336, 2013.

48. Sun L and Ye RD: Serum amyloid A1: Structure, function and gene polymorphism. Gene 583: 48-57, 2016.

This work is licensed under a Creative Commons Attribution-NonCommercial-NoDerivatives 4.0 International (CC BY-NC-ND 4.0) License. 